teaching would be improved greatly by courses of this type, universities would change only slowly and would for a long time offer courses which might inhibit rather than extend the skills and attitudes developed in schools. If the progress in schools could be matched in universities, they might produce graduates whose habits of active and independent enquiry would cause difficulties in industry where the traditional structures often left little scope for young employees with such attitudes.

When implications for first year physics and engineering courses in universities were discussed, several speakers agreed that a change in attitude to the teaching of science and engineering would be needed. But it was clear that any policy to encourage students in higher education to learn in a new way by different patterns of teaching might face severe difficulties because of constraints on staffing, timing and space. New developments in university teaching, however, were quoted and if the response of participants at the conference is a reliable guide, then higher education will adapt to take advantage of changes if detailed information about these changes can be presented in good time to a sufficiently large number of teachers.

PESTS

\section{Rats March On}

THE four year campaign by the Ministry of Agriculture to contain the spread of rats resistant to Warfarin has recently been called off. For the time being, rats will have to be controlled by conventional rodenticides. These poisons-arsenic, zinc phosphide or fluoroacetamide-are acute and they work on a single dose, provided that the rat ingests a sufficient amount. There is, however, no means of ensuring that household pets and other animals are safe from accidental poisoning. The skill of the operator is what matters.

Warfarin is by far the most efficient and safest way to destroy rats. It is slow to exert its toxic effect so that several doses are needed, thus reducing the risk of accidental poisoning. Moreover, the rats are then unable to associate their illness with the food source, and do not learn to avoid the Warfarin bait. The material is an anticoagulant, which functions by interfering with the ability of the blood to clot. Chemically, Warfarin has a structure similar to that of vitamin $\mathbf{K}$, and one of its effects is to block the synthesis of clotting factors in the liver. The action of vitamin $\mathrm{K}$ is also blocked by Warfarin, and in fact rats resistant to Warfarin have an exaggerated vitamin $K$ requirement.

Anticoagulants were in worldwide use, with much success, until outbreaks of resistance were discovered in 1960 in Scotland, Denmark and Wales. The continued use of Warfarin in rat control killed the sensitive rats, giving the resistant rats an opportunity to spread. Apparently the resistance is controlled by a single dominant gene, which means that resistance occurs in most of the offspring of resistant parents. The artificial selection operated by humans, in the continued use of Warfarin, greatly assists the resistant rats to spread. The resistant rats are at a disadvantage because of their large requirement for vitamin $K$. They would probably gradually die out if Warfarin ceased to be used.

The Ministry of Agriculture attempted to halt the march of the resistant rats by throwing a cordon around the affected areas. The three-mile-wide ring in Montgomeryshire and Shropshire was meant as a holding action to give the laboratories sufficient time to develop an entirely safe rodenticide. Landowners were warned to use only conventional rodenticides within the ring. The rats were spreading at 3 miles a year, but the cordon seems to have checked them until fairly recently. The scheme failed because some landowners continued to use Warfarin within the ring, thus undermining the ministry's effort. In addition, the outbreak of foot and mouth disease reduced the mobility of the ministry team.

The fact that resistance is easily transferred and that rats tend to migrate in search of food means that resistance will be appearing in the cities before long, provided the resistant rats can get hold of sufficient greenstuff to satisfy their vitamin K requirement. The ministry is testing new drugs as a matter of high priority to avoid the unpleasant prospect of the use of highly toxic conventional poisons in cities and towns. Norbormide is one possibility although it is not as safe as Warfarin. Two other unspecified drugs are undergoing field testing by the ministry at present.

\section{FOUNDATIONS}

\section{From ' $Q$ ' and 'F' to Nuffield}

Professon Clifford Butler, professor of physics at Imperial College, London, has been named as the next director of the Nuffield Foundation. He will take over on January 1, 1971, to fill the position left by $\mathrm{Mr}$ Brian Young, who takes up his appointment next month as Director-general of the Independent Television Authority.

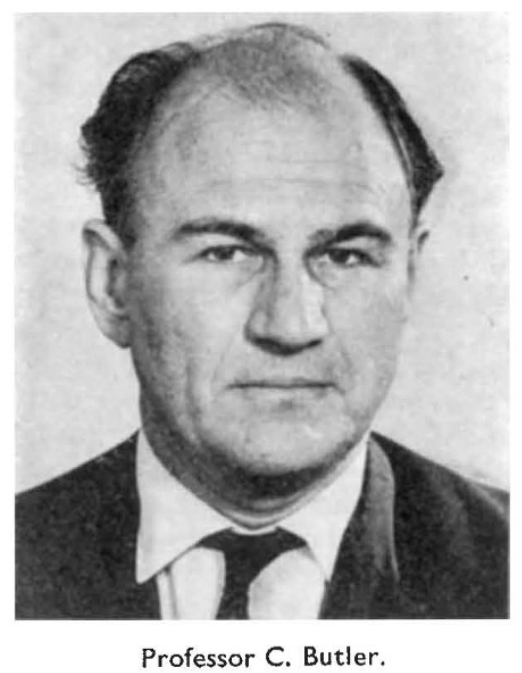

Professor Butler will take over the directorship of an organization which distributes more than $£ 1$ million in research grants every year, but which is perhaps best known for its sponsorship of schools teaching projects. The new director of the foundation is certainly no stranger to this type of work-he was joint chairman of the committee which came up with the controversial proposals for ' $Q$ ' and ' $F$ ' level examinations in the sixth form, and he is a member of the Standing Committee on University Entrance. 